\title{
Kajian Kes Tempat Perlaksanaan Pengajaran dan Pembelajaran Pedidikan Islam Sekolah Menengah Rendah di Johor
}

\author{
Nazirah Hamdan*, Kamarul Azmi Jasmi \\ Fakulti Tamadun Islam, Universiti Teknologi Malaysia, 81310 UTM Johor Bahru, Johor, Malaysia \\ *Corresponding author: nazirah24@live.utm.my
}

\begin{abstract}
A variety of teaching and learning of Islamic Education is one of the elements that is been practiced by the Islamic Education teachers (GPI) in Johor. Therefore, this research is mainly focused on the venue for implementation the teaching and learning process of the subject, in order to create an effective and innovative learning session. Hence, in this study, the main data are supported by analysis documents and observation which collected from formal interviews of seven participants which are been considered as the main respondent. Other than that forty-two informants were identified in order to obtain more information as the supported to the main respondent. The transcript of the interviews data are analysed via N' Vivo 7.0 software to create a theme, subthemes and sub-themes. The outcome of this study showed that there are five main areas that make up the pattern and most frequent areas of teaching and learning process are prayer room, library, classrooms, school region and audio visual room. This case study creates an outcome for Teaching and Learning Points of Islamic Education Model.
\end{abstract}

Keywords: Place of teaching and learning; prayer room, library, classroom; school region; school district school areas

Abstrak

Kepelbagaian tempat pengajaran dan pembelajaran Pendidikan Islam merupakan salah satu elemen yang sering dipraktikkan oleh guru Pendidikan Islam (GPI) di Johor. Kajian ini cuba memfokuskan kepada tempat perlaksanaan pengajaran dan pembelajaran Pendidikan Islam oleh guru Pendidikan Islam di sekolah bagi mewujudkan suatu pembelajaran yang berkesan. Kajian kes berbentuk kualitatif ini menggunakan instrumen temubual sebagai data utama dengan disokong oleh dokumen analisis dan pemerhatian. Seramai tujuh orang peserta yang telah dipilih sebagai responden utama dan empat puluh dua orang informan telah di kenal pasti bagi mendapatkan maklumat tambahan kepada peserta respondent utama. Data temubual di transkrip dan dianalisis dalam perisian $\mathrm{N}^{`}$ Vivo 7.0 bagi membentuk tema, sub tema, dan sub-sub tema. Hasil kajian menunjukkan lima tempat utama yang membentuk pola dan sering digunakan sewaktu proses pengajaran dan pembelajaran iaitu, surau, perpustakaan, kelas, kawasan persekitaran sekolah, dan bilik alat pandang dan dengar. Dapatan kajian ini menghasilkan Model Tempat Pengajaran dan Pembelajaran (P\&P) Pendidikan Islam.

Kata Kunci: Tempat pengajaran dan pembelajaran; surau; perpustakaan; kelas; dan persekitaran sekolah

(C) 2016 Penerbit UTM Press. All rights reserved

\subsection{PENGENALAN}

Bertepatan dengan arus pembangunan pendidikan negara menuju wawasan 2020, setiap sekolah sewajarnya telah menyediakan insfastruktur dan kemudahan yang lengkap. Hal ini perlu bagi memastikan setiap proses pengajaran dan pembelajaran dapat berjalan dengan lancar (Kamarul Azmi, Abd. Halim \& Mohd Izham, 2011). Perkembangan pendidikan di negara kita pada hari ini dapat dilihat dari kewujudan pelbagai ketegori sekolah menengah kebangsaan yang memiliki status tertentu seperti sekolah kluster kecemerlangan, sekolah kluster, sekolah bestari, sekolah berasrama penuh, dan sekolah harian (Kementerian Pelajaran Malaysia, 2012) . Keadaan ini menunjukkan komitmen dari pihak kementerian pendidikan terhadap aspek pendidikan nasional. Jika dilihat dalam aspek pengajaran dan pembelajaran, proses penyampaian atau pemindahan ilmu adalah suatu perkara yang penting. Maka proses pengajaran dan pembelajaran seharusnya berlangsung dalam suasana yang kondusif agar pelajar dapat belajar tanpa mengalami sebarang gangguan dan guru dapat menyampaikan dengar baik tanpa perlu memikirkan masalah yang mungkin timbul kesan daripada tempat dan persekitaran yang kurang selesa (Ruzita, Ungku Norulkamar, Noor Zainab, Lokman, Azian, Fauziah, \& Aminah, 2004) .

Sehubungan itu, pihak kementerian pendidikan sewajarnya memberikan sokongan dan peruntukan yang mencukupi agar setiap sekolah di Malaysia secara amnya mampu untuk menyediakan tempat pembelajaran yang lebih selesa kepada guru dan pelajar seperti surau, bilik atau makmal komputer, makmal-makmal sains, bilik tayangan, dan sebagainya (KPM, 2013; Falcinelli \& Laici, 2011). Hamdi, Abd. Halim, Rosadah, \& Safani (2012) juga mendapati bahawa bahan bantu mengajar (BBM) disimpan di tempat proses pengajaran dan pembelajaran $(\mathrm{P} \& \mathrm{P})$ berlaku iaitu sama ada di bilik Pendidikan Islam, bilik ICT, bilik darjah, surau, dan bilik stor yang khusus. Segala bentuk kemudahan dan infastruktur yang dinyatakan ini pada hakikatnya membantu kelancaran proses pengajaran dan pembelajaran (Masoud, Masoud, \& Masoumeh, 2012). Hal ini kerana, setiap pelajar mempunyai kecenderungan yang berbeza. Sebilangan besar pelajar lebih suka sekiranya pengajaran disampaikan dalam bentuk visual seperti carta alir, gambar rajah, skema, dan ada juga yanglebih gemar jika penyampaian guru dalam bentuk verbal seperti kuliah (Mohd Noor Badlilshah, 2007). 
Bertepatan dengan prinsip Pendidikan Islam bagi membentuk generasi beriman dan memiliki kefahaman agama yang kukuh, institusi masjid khasnya dan surau amnya memainkan peranan yang besar sebagaimana yang telah ditunjukkan oleh baginda Rasulullah s.a.w. Sejarah melakarkan bahawa masjid berperanan sebagai pusat ilmu pengetahuan, dan tradisi ini telah diteruskan oleh para sahabat baginda, golongan tabi' dan tabi' in yang lain dalam proses menyebarkan ilmu pengetahuan. Sebagai contoh, imam-imam besar seperti Shafii, Abu Hanifah, Malik, dan Ahmad menjadikan masjid sebagai pusat penyebaran ilmu pengetahuan (Abd. Halim, 2013). Sebagaimana firman Allah s.w.t, yang bermaksud "hanyasanya yang layak memakmurkan (menghidupkan) masjid-masjid Allah itu ialah orang-orang yang beriman kepada Allah dan hari akhirat serta mendirikan sembahyang, dan menunaikan zakat, dan tidak takut melainkan kepada Allah, (dengan adanya sifat-sifat tersebut) maka adalah diharapkan mereka menjadi dari golongan yang mendapat petunjuk" (surah At-Taubah, 9: 18). Justeru, kajian ini bertujuan bagi mengupas di manakah tempat yang menjadi pilihan guru pendidikan Islam dalam melaksanakan proses pengajaran dan pembelajaran di sekolah.

\subsection{OBJEKTIF DAN PERSOALAN KAJIAN}

Kajian ini adalah bagi Melihat Penggunaan Tempat Proses Pengajaran dan Pembelajaran (P\&P) dalam Kalangan Guru Pendidikan Islam (GPI) Peringkat Menengah Rendah. Di samping itu juga kajian ini dapat mengenalpasti tempat yang sering digunakan oleh para asatizah di sekolah. Persoalan kajian yang dapat diutarakan ialah "di manakah tempat yang sering digunapakai oleh golongan ustaz dan ustazah di sekolah dalam perlaksanaan bagi pengajaran dan pembelajaran subjek Pendidikan Islam?", "di manakah tempat yang membentuk pola kekerapan penggunaannya dalam kalangan ustaz dan ustazah di sekolah?", serta "adakah GPI menggunakan tempat lain sebagaimana kebiasaannya dalam proses P\&P Pendidikan Islam?"

\subsection{METODOLOGI KAJIAN}

Cohen dan Manion (1996) menyatakan bahawa metodologi adalah pendekatan yang digunakan dalam penyelidikan pendidikan bagi pengumpulan data. Kajian yang dijalankan ini adalah berbentuk kualitatif atau lebih menjurus kepada kajian kes atau lebih tepat lagi sebagai kajian pelbagai kes (multiple case) sebagai salah satu bentuk kesahan data kajian (Merriam, 2002). Metodologi utama yang digunakan oleh pengkaji dalam kajian ini adalah temubual bagi mendapatkan maklumat yang khusus dalam mengumpulkan maklumat.

Kajian temubual merupakan sesuatu yang unik kerana ia melibatkan proses pengumpulan data melalui lisan antara dua pihak secara langsung (Sang, 2010). Kaedah ini digunakan kerana untuk mengkaji beberapa individu yang terpilih atau sesuai digunakan dalam kajian yang memerlukan pengumpulan data daripada sampelan yang besar (Othman, 2014). Seterusnya, data yang telah dikumpulkan ini telah diolah, dianalisis dengan menggunakan perisian N'Vivo 7.0, dan kemudian ditafsirkan berdasarkan kerangka kajian yang telah ditetapkan. Hasil temubual ini kemudiannya akan ditranskrip menjadi data naratif dan seterusnya analisis dibuat dengan menggunakan perisian N' Vivo 7.0 bagi membina tema dan sub-sub tema kajian.

Keesahan dan kebolehpercayaan dalam kajian ini adalah sebagaimana yang dicadangkan oleh Bogdan dan Miklen (2003) iaitu, pengesahan inventori soalan separa berstruktur yang telah disahkan oleh penyelia dan pakar bidang Pendidikan Islam, menjalankan kajian rintis sebelum kajian lapangan yang sebenar, triangulasi data, laporan nota lapangan dan diari, pengesahan pakar terhadap tema kajian yang dibina, dan pengiraan Cohen Kappa terhadap pensetujuan pakar terhadap tema kajian tersebut.

Justeru, kajian ini melibatkan seramai 7 orang GPI di samping 14 orang rakan GPI, 14 orang pelajar, dan 7 orang pihak atasan GPI yang terpilih. Kaedah pemerhatian terhadap sample kajian dan analisis dokumen dilaksanakan sebagai sokongan kepada data temubual. Kriteria pemilihan GPI ini adalah, (1) berpengalaman mengajar 1- 5 tahun, (2) berpengalaman mengajar 5-10 tahun, (3) berpengalaman mengajar 10 tahun ke atas, (4) guru cemerlang Pendidikan Islam, (5) peratusan sekolah mencapai 95\% ke atas dalam subjek Pendidikan Islam Peperiksaan Menengah Rendah (PMR).

\subsection{PENGANALISAAN \& DAPATAN KAJIAN}

Fokus utama yang menjadi perbincangan artikel ini merujuk kepada objektif yang mendasari kajian iaitu "Melihat Penggunaan Tempat Proses Pengajaran dan Pembelajaran (P\&P) dalam Kalangan Guru Pendidikan Islam (GPI) Peringkat Menengah Rendah". Hasil dapatan kajian yang diperolehi telah menjelaskan secara terperinci berkenaan penggunaan tempat proses P\&P dalam kalangan GPI di sekolah. Jadual 1hingga Jadual 5 merupakan dapatan kajian yang diperolehi berdasarkan majoriti amalan penggunaan tempat perlaksanaan P\&P yang digunakan oleh GPI. Berdasarkan jadual tersebut, pola tempat perlaksanaan P\&P ini dipersetujui oleh majoriti GPI dari S1 hingga S7 iaitu surau, perpustakaan, kelas, kawasan persekitaran sekolah, dan bilik Alat Pandang dan Dengar (APD). Hanya empat tempat yang tidak membentuk pola seperti makmal komputer, bilik Pendidikan Islam, dewan terbuka, dan kantin sebagaimana yang tertera pada Jadual 6 hingga Jadual 9.

Surau menjadi tempat pilihan utama bagi setiap GPI S1-S7 dalam proses P\&P Pendidikan Islam di sekolah bagi memudahkan pemahaman para pelajar di samping memudahkan GPI untuk mengajar topik ibadah, perlaksanaan atau praktikal amali pengajaran, seperti amali solat, pengurusan jenazah, tayamum dan sebagainya (GPIS1, 2012. 154-156; GPIS2, 2012: 318; GPIS3, 2012: 787; GPIS4, 2014: 212; GPIS5, 2014: 225; GPIS6, 2014: 174). Penggunaan surau dalam P\&P di S7 pula dibuktikan melalui temubual dengan (P1S7, 2014: 109; P2S7, 2014: 109; PAGPIS7, 2014: 195; R1GPIS7, 2014: 188). Selain itu, hasil kajian menunjukkan bahawa pelajar lebih seronok untuk belajar di surau serta pengajaran menjadi lebih berkesan. Sebagai bukti GPIS5 (2014: 225) ada menjelaskan:

"Lokasi pengajaran, bila buat di surau ini saya rasa lebih berkesan..bila tanya pelajar pun mereka lebih seronok, perasaan pun memang lain..sedangkan saya tanya mereka, awak tak penat ke turun dari tingkat 4, jalan ke surau? Tak Ummi..memang kami seronok.. ", 
Petikan ini menjelaskan bahawa walaupun para pelajar perlu bergerak meninggalkan kelas untuk ke surau, tidak menjadi masalah kepada mereka kerana pengajaran dan pembelajaran Pendidikan Islam menjadi lebih seronok jika dibuat di surau (PAGPIS5, 2014: 142).

Jadual Penggunaan surau ketika P\&P

\begin{tabular}{|c|c|c|c|c|c|c|c|c|c|}
\hline \multicolumn{7}{|c|}{ Data Temu Bual } & $\mathrm{AD}$ & OS & Jumlah \\
\hline & GPIS1-7 & PAGPIS1-7 & R1GPIS1-7 & R2GPIS1-7 & P1S1-7 & P2S1-7 & ADS1-7 & OS1-7 & $\sum$ \\
\hline S1 & $\mathrm{x}$ & $\mathrm{x}$ & $\mathrm{x}$ & - & - & - & - & $\mathrm{x}$ & $\mathrm{x}$ \\
\hline S2 & $\mathrm{x}$ & - & - & - & - & $\mathrm{x}$ & - & - & $\mathrm{x}$ \\
\hline S3 & $\mathrm{x}$ & - & $\mathrm{x}$ & $\mathrm{X}$ & $\mathrm{x}$ & - & - & - & $\mathrm{x}$ \\
\hline S4 & $\mathrm{x}$ & $\mathrm{x}$ & $\mathrm{x}$ & $\mathrm{x}$ & $\mathrm{x}$ & $\mathrm{x}$ & - & $\mathrm{x}$ & $\mathrm{x}$ \\
\hline S5 & $\mathrm{x}$ & $\mathrm{x}$ & - & $\mathrm{x}$ & $\mathrm{x}$ & - & - & $\mathrm{x}$ & $\mathrm{x}$ \\
\hline S6 & $\mathrm{x}$ & $\mathrm{x}$ & $\mathrm{x}$ & $\mathrm{x}$ & $\mathrm{x}$ & - & - & - & $\mathrm{x}$ \\
\hline S7 & - & $\mathrm{x}$ & $\mathrm{x}$ & - & $\mathrm{x}$ & $\mathrm{x}$ & - & $\mathrm{x}$ & $\mathrm{x}$ \\
\hline
\end{tabular}

Keterangan: ' $x$ ' bermakna mewakili data. S1-S7- Sekolah 1 hingga Sekolah 7, GPI- Guru Pendidikan Islam, PAGPI- Pihak Atasan Guru Pendidikan Islam, R1- Rakan 1 Guru Pendidikan Islam, R2- Rakan 2 Guru Pendidikan Islam, P1GPI- Pelajar 1 Guru Pendidikan Islam, P2GPI- Pelajar 2 Guru Pendidikan Islam, AD- Analisis Dokumen, dan OS- Observasi

Berdasarkan data utama iaitu melalui temu bual yang dibuat, pengkaji mendapati hanya GPIS3, GPIS4, dan GPIS5 sahaja yang menggunakan perpustakaan sewaktu subjek Pendidikan Islam. Menurut GPIS3 (2012: 768-770):

\begin{abstract}
"biasanya saya bawak ke pusat sumber saya suruh cari bahan dekat pusat sumber semua.. buku-buku..lepas dia orang buat rujukan..orang yang buat bahan aaa buat kertas majung tu pastu bentang"
\end{abstract}

(GPIS3:PP/TPT/PS)

Kenyataan ini disokong melalui data temubual bersama P1S3 (2012: 88) yang menyatakan bahawa:

"Ustaz bawa kami ke library untuk cari bahan-bahan berkenaan bulan ramadhan jadi ustaz banyak buat pendekatan kepada hadis lah.."

(P1S3:PP/TPT/PS)

Jadual 2 Penggunaan perpustakaan ketika P\&P

\begin{tabular}{|c|c|c|c|c|c|c|c|c|c|}
\hline \multicolumn{7}{|c|}{ Data Temu Bual } & $\mathrm{AD}$ & OS & Jumlah \\
\hline & GPIS1-7 & PAGPIS1-7 & R1GPIS1-7 & R2GPIS1-7 & P1S1-7 & P2S1-7 & ADS1-7 & OS1-7 & $\sum$ \\
\hline S1 & - & - & - & - & - & - & - & - & - \\
\hline S2 & - & - & - & - & $\mathrm{x}$ & - & - & - & $\mathrm{x}$ \\
\hline S3 & $\mathrm{x}$ & - & $\mathrm{x}$ & - & $\mathrm{x}$ & $\mathrm{x}$ & - & - & $\mathrm{x}$ \\
\hline S4 & $\mathrm{x}$ & $\mathrm{x}$ & $\mathrm{x}$ & $\mathrm{x}$ & - & - & - & - & $\mathrm{x}$ \\
\hline S5 & $\mathrm{x}$ & - & - & - & - & - & - & - & $\mathrm{x}$ \\
\hline S6 & - & - & - & - & - & - & - & - & - \\
\hline S7 & - & - & $\mathrm{x}$ & - & - & - & - & - & $\mathrm{x}$ \\
\hline
\end{tabular}

Keterangan: ' $x$ ' bermakna mewakili data. S1-S7- Sekolah 1 hingga Sekolah 7, GPI- Guru Pendidikan Islam, PAGPI- Pihak Atasan Guru Pendidikan Islam, R1- Rakan 1 Guru Pendidikan Islam, R2- Rakan 2 Guru Pendidikan Islam, P1GPI- Pelajar 1 Guru Pendidikan Islam, P2GPI- Pelajar 2 Guru Pendidikan Islam, AD- Analisis Dokumen, dan OS- Observasi.

Dalam hal penggunaan kelas sebagaimana yang telah sedia ada, kajian mendapati GPIS2 (2012: 318) dan GPIS6 (2014: 194) menggunakan kemudahan ini sebagaimana biasa. Namun begitu, GPIS3, GPIS4 dan GPIS7 turut menggunakan kemudahan kelas dalam pengajaran subjek Pendidikan Islam di sekolah melalui data temubual bersama rakan-rakan dan pelajar GPI.

Jadual 3 Penggunaan kelas ketika P\&P

\begin{tabular}{|c|c|c|c|c|c|c|c|c|c|}
\hline \multicolumn{7}{|c|}{ Data Temu Bual } & $\mathrm{AD}$ & OS & Jumlah \\
\hline & GPIS1-7 & PAGPIS1-7 & R1GPIS1-7 & R2GPIS1-7 & P1S1-7 & P2S1-7 & ADS1-7 & OS1-7 & $\sum$ \\
\hline S1 & - & - & - & - & - & - & - & - & - \\
\hline S2 & $\mathrm{x}$ & - & - & - & - & - & - & - & $\mathrm{x}$ \\
\hline S3 & - & - & - & $\mathrm{x}$ & - & - & - & - & $\mathrm{x}$ \\
\hline S4 & - & - & $\mathrm{x}$ & - & - & - & - & - & $\mathrm{x}$ \\
\hline S5 & - & - & - & - & - & - & - & - & - \\
\hline S6 & $\mathrm{x}$ & - & - & $\mathrm{x}$ & - & - & - & $\mathrm{x}$ & $\mathrm{x}$ \\
\hline S7 & - & - & $\mathrm{x}$ & - & $\mathrm{x}$ & $\mathrm{x}$ & - & - & $\mathrm{x}$ \\
\hline
\end{tabular}

Keterangan: 'x' bermakna mewakili data. S1-S7- Sekolah 1 hingga Sekolah 7, GPI- Guru Pendidikan Islam, PAGPI- Pihak Atasan Guru Pendidikan Islam, R1- Rakan 1 Guru Pendidikan Islam, R2- Rakan 2 Guru Pendidikan Islam, P1GPI- Pelajar 1 Guru Pendidikan Islam, P2GPI- Pelajar 2 Guru Pendidikan Islam, AD- Analisis Dokumen, dan OS- Observasi.

Antara usaha yang dilakukan oleh GPI untuk memberikan pemahaman serta penghayatan kepada para pelajar khususnya dalam memahami topik akidah, kawasan persekitaran sekolah menjadi salah satu tempat berlangsungnya aktiviti pengajaran. Hal ini dapat dibuktikan melalui 
hasil kajian temubual di S3, S4, S5 dan S6 sebagaimana yang tertera dalam Jadual 4. Sebagaimana yang telah disebutkan oleh (P1S3, 2012. 253, 257, 261,266):

"kami akan melihat alam sekitar dan kami akan kaitan dengan pembelajaran..Macam selalu kalau selalu masa tu ustaz bawa kami keluar sebab masa tu kami belajar tentang topik sifat Allah asmaulhusna..Allah maha mengetahui, kenapa..nanti ustaz. akan bawa kami dekat pokok tu tanya kenapa pokok tu dia macam ni.."

(P1S3:PP/TPT/PSEK)

Jadual 4 Persekitaran sekolah ketika P\&P

\begin{tabular}{|c|c|c|c|c|c|c|c|c|c|}
\hline \multicolumn{7}{|c|}{ Data Temu Bual } & $\mathrm{AD}$ & OS & Jumlah \\
\hline & GPIS1-7 & PAGPIS1-7 & R1GPIS1-7 & R2GPIS1-7 & P1S1-7 & P2S1-7 & ADS1-7 & OS1-7 & $\sum$ \\
\hline S1 & - & - & - & - & - & - & - & - & - \\
\hline $\mathrm{S} 2$ & - & - & - & - & - & - & - & - & - \\
\hline S3 & - & $\mathrm{x}$ & $\mathrm{x}$ & $\mathrm{x}$ & $\mathrm{X}$ & $\mathrm{x}$ & - & - & $\mathrm{x}$ \\
\hline S4 & - & $\mathrm{x}$ & - & - & - & - & - & - & $\mathrm{x}$ \\
\hline S5 & - & - & - & - & - & - & - & - & - \\
\hline S6 & - & - & $\mathrm{x}$ & - & - & - & - & - & $\mathrm{x}$ \\
\hline S7 & - & $\mathrm{x}$ & - & - & - & - & - & - & $\mathrm{x}$ \\
\hline
\end{tabular}

Keterangan: ' $x$ ' bermakna mewakili data. S1-S7- Sekolah 1 hingga Sekolah 7, GPI- Guru Pendidikan Islam, PAGPI- Pihak Atasan Guru Pendidikan Islam, R1- Rakan 1 Guru Pendidikan Islam, R2- Rakan 2 Guru Pendidikan Islam, P1GPI- Pelajar 1 Guru Pendidikan Islam, P2GPI- Pelajar 2 Guru Pendidikan Islam, AD- Analisis Dokumen, dan OS- Observasi.

Penggunaan bilik alat pandang dan dengar juga merupakan pola di mana ia menjadi pilihan GPI dalam pengajaran dan pembelajaran Pendidikan Islam, sebagaimana yang ditunjukkan dalam Jadual 5. Kajian mendapati bilik APD digunakan dengan sebaik mungkin oleh GP1S4, GPIS5, GPIS6, dan GPIS7. Penggunaan bilik APD dalam kalangan GPI ini selain daripada untuk menggunakan LCD, adalah bagi memaparkan tayangan filem yang berunsur sirah Islamiah sebagaimana yang dinyatakan oleh GPIS4 (2014: 213):

“ataupun kalau waktu P\&P untuk sirah ke saya akan pergi ke bilik tayang lah..”

(GPIS4:PP/TPT/BAPD)

Jadual 5 Penggunaan bilik Alat Pandang dan Dengar ketika P\&P

\begin{tabular}{|c|c|c|c|c|c|c|c|c|c|}
\hline \multicolumn{7}{|c|}{ Data Temu Bual } & $\mathrm{AD}$ & $\mathrm{OS}$ & Jumlah \\
\hline & GPIS1-7 & PAGPIS1-7 & R1GPIS1-7 & R2GPIS1-7 & P1S1-7 & P2S1-7 & ADS1-7 & OS1-7 & $\sum$ \\
\hline $\mathrm{S} 1$ & - & - & - & - & - & - & - & - & - \\
\hline $\mathrm{S} 2$ & - & - & - & - & - & - & - & - & - \\
\hline S3 & - & - & - & - & - & - & - & - & - \\
\hline $\mathrm{S} 4$ & $\mathrm{x}$ & $\mathrm{x}$ & - & - & - & - & - & - & $\mathrm{x}$ \\
\hline S5 & $\mathrm{x}$ & - & - & - & - & - & - & - & $\mathrm{X}$ \\
\hline S6 & - & $\mathrm{X}$ & - & - & - & - & - & - & $\mathrm{x}$ \\
\hline S7 & - & $\mathrm{x}$ & - & - & - & - & - & - & $\mathrm{x}$ \\
\hline
\end{tabular}

Keterangan: ' $x$ ' bermakna mewakili data. S1-S7- Sekolah 1 hingga Sekolah 7, GPI- Guru Pendidikan Islam, PAGPI- Pihak Atasan Guru Pendidikan Islam, R1- Rakan 1 Guru Pendidikan Islam, R2- Rakan 2 Guru Pendidikan Islam, P1GPI- Pelajar 1 Guru Pendidikan Islam, P2GPI- Pelajar 2 Guru Pendidikan Islam, AD- Analisis Dokumen, dan OS- Observasi.

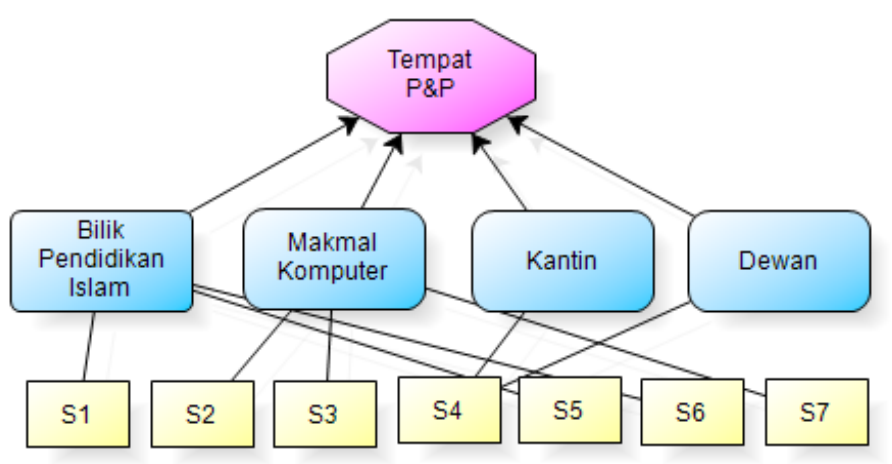

Carta 1 Penggunaan Tempat di S1-S7 yang tidak membentuk pola

Selain daripada lima tempat pengajaran dan pembelajaran yang membentuk pola, masih terdapat empat tempat yang tidak mewakili sebahagian besar daripada GPI di S1-S8 sebagaimana yang ditunjukkan dalam Carta 1. Carta 1 jelas menunjukkan bahawa tempat yang sering digunakan oleh GPI ialah makmal komputer dan bilik Pendidikan Islam, manakala kantin dan dewan terbuka hanya wujud di S4.

Kesimpulannya melalui hasil temubual, pemerhatian, dan analisis dokumen yang telah dijalankan terhadap GPI di S1-S7 terdapat sebanyak sembilan tempat perlaksanaan pengajaran dan pembelajaran Pendidikan Islam termasuklah tempat yang dapat membentuk pola 
dan tidak membentuk pola. Tempat yang membentuk pola mencatatkan kekerapan penggunaannya oleh GPI di S1-S7, manakala tempat yang tidak membentuk pola menunjukkan kekerapan penggunaannya adalah kurang serta tidak menyeluruh dalam kalangan GPI di sekolah yang dikaji.

\subsection{PERBINCANGAN}

Dapatan kajian memperlihatkan lima pola utama terhadap Penggunaan Tempat Proses Pengajaran dan Pembelajaran (P\&P) dalam kalangan Guru Pendidikan Islam (GPI) peringkat menengah rendah, iaitu surau, perpustakaan, kelas, kawasan persekitaran sekolah, dan bilik Alat Pandang dan Dengar (APD). Selain itu, terdapat beberapa item yang tidak membentuk pola kajian iaitu, dewan terbuka, makmal komputer, kantin, dan bilik Pendidikan Islam. Oleh yang demikian, kajian ini jelas menunjukkan bahawa setiap GPI di sekolah menggunakan kemudahan surau dalam proses P\&P Pendidikan Islam khususnya dalam menyampaikan topik ibadah dan akhlak.

Pada hakikatnya, penggunaan surau dalam P\&P Pendidikan Islam ini adalah selaras dengan metod penyampaian dakwah yang telah digunakan sejak dari zaman awal perkembangan ajaran Islam. Hal ini dapat dilihat daripada pembinaan yang pertama didirikan oleh baginda Rasul s.a.w sejurus tiba di kota Madinah ialah masjid. Peristiwa penghijrahan ini menjadi satu titik tolak kepada perkembangan agama Islam. Sebaik tiba di kota Madinah, baginda Rasul s.a.w dan para sahabat telah mendirikan masjid yang dikenali sebagai Masjid Quba'. Selain itu, masjid Nabawi turut menjadi pusat penyebaran ilmu Islam, dan selepas pembukaan kota Mekah Baitullah juga menjadi pusat penyebaran Islam untuk seluruh kaum muslimin kerana Baitullah adalah tempat perhimpunan umat Islam bagi menunaikan ibadah haji Ahmad (2000). Justeru, pembinaan masjid ini menjadi simbol utama bagi usaha perpaduan umat Islam di samping pusat perkembangan ilmu pengetahuan (Mohd Mokhtar, 2003).

Oleh itu, penggunaan surau adalah sinonim dalam proses penyampaian pengajaran dan pembelajaran Pendidikan Islam di sekolah-sekolah pada hari ini. Penggunaan surau pada hakikatnya secara tidak langsung dapat memudahkan serta melancarkan proses penyampaian guru kerana ia sering melibatkan penglibatan pelajar khususnya perlaksanaan amali seperti solat, tayamum, berwuduk, dan pengurusan jenazah. Selain daripada itu, surau juga digunakan dalam perlaksanaan program yang bercorak keislaman seperti sambutan hari kebesaran Islam, program ibadah dan kerohanian, serta solat berjemaah (Abd. Halim, Shahrin, \& Tajul Ariffin, 2003; Mohd Yusuf, 2010). Hal ini bertepatan dengan prinsip asas KBSM dalam melahirkan insan seimbang dari aspek emosi, rohani, intelek, dan jasmani dapat direalisasikan jika surau digunakan secara optimum (Tajul Ariffin \& Abd. Rahim, 1987; KPM, 2012). Hal ini selaras dengan dapatan kajian Abd. Halim et al. (2003) yang mendapati bahawa program sambutan hari kebesaran Islam seperti maal hijrah dan maulidur Rasul, serta gotong-royong sering diadakan di surau. Aktiviti seperti pembelajaran kelas al-Quran, amali solat, wuduk, PAFA, program ibadah dan kerohanian, program pembinaan insan, kaunseling dan sahsiah pelajar turut di adakan di surau-surau sekolah.

Perpustakaan atau Pusat Sumber merupakan dapatan kedua yang menjadi amalan tempat perlaksanaan P\&P Pendidikan Islam di sekolah. Menurut Jamaludin, Muhammad, \& Abd. Rashid (2000) pengajaran berasaskan pusat sumber sekolah merupakan satu bentuk usaha guru bagi melengkapkan pendekatan dan strategi pengajaran yang melibatkan pelajar supaya dapat belajar melalui penggunaan sumber-sumber pembelajaran. Hal ini adalah kerana, pusat sumber merupakan salah satu pusat yang penting bagi setiap sekolah kerana ia berperanan dalam menyediakan bahan-bahan pembelajaran, selain dapat meningkatkan kualiti pengajaran dan pembelajaran sekolah (Nor Diana, Nor Ezan, \& Zailani, 2011). Hal ini disokong oleh kajian Agatha Francis (2011) yang menyatakan bahawa pusat sumber turut membantu pelajar dalam pencarian bahan, mengakses maklumat dan membuat rujukan serta melaksanakan aktiviti lain. Hal ini berikutan daripada peranan komputer dan ICT yang turut membantu dalam melancarkan lagi proses pengajaran dan pembelajaran (Ashinida, Afendi, \& Mohd Shabri, 2004; Tejo, 2012; Johari, Nor Hasniza, \& Rohaya, 2014). Pengurusan dan penyediaan bilik alat pandang dan dengar (APD) juga adalah tertakluk dibawah seliaan pusat sumber sekolah (KPM, 2013).

Berikutnya, jika dilihat dari sudut penggunaan kelas dan kawasan persekitaran sekolah, ia turut menjadi pilihan kepada GPI dalam proses penyampaian P\&P. Keadaan ini dibuktikan daripada data temubual kajian bersama yang menyatakan, R2GPIS3 (2012) "kita boleh bawa pelajar tu, tadi kita nak ajar tentang bab kewujudan Allah... Kita mungkin boleh bawa pelajar tu dibawah pokok ke...". Pernyataan ini menunjukkan bahawa alam persekitaran turut menjadi salah satu daripada bentuk atau bahan dalam menyampaikan ajaran islam dengan lebih berkesan kepada pelajar. Pada hakikatnya, kawasan persekitaran sekolah juga adalah bersesuaian untuk menjadi tempat berlangsungnya proses pengajaran dan pembelajaran pendidikan Islam di sekolah. Hal ini kerana, alam persekitaran seperti pokok-pokok, langit, udara, batu-batan, rumput, dan sebagainya secara tidak langsung dapat dijadikan sebagai salah satu bahan bantu mengajar khususnya dalam menyampaikan bab akidah, dan penciptaan alam kepada pelajar. Bertepatan dengan begitu banyak nas dan dalil yang terkandung dalam al-Quran berkaitan suruhan atau perintah Allah swt agar manusia memikirkan tentang kejadian alam bagi menambah ketaqwaan kepada Allah swt antaranya, (surah al-Baqarah, 2: 32; surah al- Dhariyat, 51: 20-21; surah al- An'am, 6:1; surah Yunus, 10: 101; surah al- Ra'd, 13:2; surah Fussilat, 41: 53; surah Ali Imran, 3: 190-191). Firman Allah swt yang bermaksud "dan adakah mereka tidak memperhatikan kejadian langit dan bumi dan segala apa yang diciptakan Allah, dan kemungkinan telah dekatnya waktu (kebinasaan) mereka? Lalu berita berita mana lagi setelah ini yang akan mereka percayai?" (Surah al-A'raf, 7: 185). Kajian yang dilakukan oleh Mohd Faeez dan Kamarul Azmi (2012) menggariskan bahawa alam persekitaran sebagai salah satu sumber bahan pengajaran dan pembelajaran Pendidikan Islam.

Pada kebiasaannya, kelas menjadi tempat utama bagi proses pengajaran dan pembelajaran di sekolah. Emmer, Evertson, Sanford, Clements, \& Worsham (1993) berpendapat persekitaran kelas yang baik meliputi empat aspek iaitu, mengelakkan sebarang halangan di ruangan laluan atau tempat pelajar sering berkumpul; menyusun bahan bantu mengajar (BBM) di tempat yang mudah di capai; memastikan pandangan guru terhadap pelajar tidak terhalang agar mudah membuat pemantauan; dan susun atur kedudukan meja pelajar yang baik bagi membolehkan pelajar melihat papan hitam, skrin LCD, ataupun simulasi yang dilalakukan oleh guru. James (2014) menyatakan, usaha mewujudkan bilik darjah yang ceria dan tersusun mampu meningkatkan produktiviti dan mengurangkan masalah salah laku pelajar. Oleh itu, bagi memastikan pengajaran dan pembelajaran dalam kelas berkesan aspek seperti pencahayaan, pengudaraan, kekemasan, kebersihan, keceriaan, susun atur tempat duduk dan sebagainya perlulah dirancang secara rapi dan teratur. Hal ini selari dengan dapatan Haliza dan Samuel (2014) yang menyatakan susun atur fizikal kelas yang baik akan menjadikan guru lebih berautoriti, memiliki stail dalam 
pengajaran, menimbulkan rasa kesepunyaan dan membolehkan interaksi dalam kelas. Bilik darjah yang teratur, kemas, dan bersih menggambarkan keselesaan kepada pelajar, seterusnya membantu guru mentadbir kelas dengan berkesan.

Justeru, persekitaran sekolah yang bersih, ceria, dan harmoni turut memainkan peranan yang penting. Oleh yang demikian, setiap warga sekolah khususnya pihak pentadbir perlu memastikan bahawa suasana sekolah aman, cantik, selamat serta memyediakan ruang belajar yang secukupnya bagi mewujudkan iklim sekolah yang berkesan (Shahril, 1997).

\subsection{CADANGAN}

Justeru, berdasarkan hasil dapatan kajian pengkaji menghasilkan satu model yang dinamakan Model Tempat Pengajaran dan Pembelajaran (P\&P) Pendidikan Islam. Model ini digambarkan oleh pengkaji sebagaimana yang tertera pada Rajah 1.

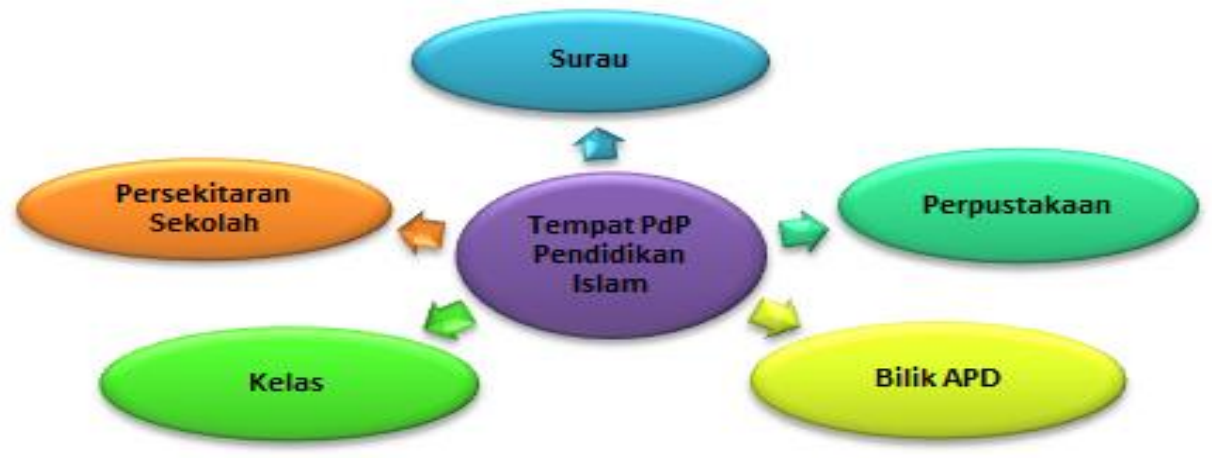

Rajah 1 Model Tempat Pengajaran dan Pembelajaran (P\&P) Pendidikan Islam

Berdasarkan Rajah 1, kesemua tempat ini boleh digunakan dengan sebaik yang mungkin oleh setiap guru Pendidikan Islam secara amnya di Malaysia. Namun, adalah lebih baik sekiranya setiap sekolah menyediakan kemudahan infasktruktur yang lengkap bukan sahaja demi keselesaan guru malahan juga kepada pelajar bagi meningkatkan tahap motivasi diri demi kecemerlangan sekolah selaras dengan prinsip dan falsafah Pendidikan Islam. Kemudahan prasarana dan infraksturtur yang lengkap serta penggunaan bahan bantu mengajar yang pelbagai dapat membantu meningkatkan motivasi guru dan pelajar agar pembelajaran lebih bermakna. Oleh itu, tempat pengajaran dan pembelajaran perlu mempunyai gabungan elemen fizikal, emosi, dan sosial. Hal ini kerana setiap elemen tersebut bakal mempengaruhi guru dan pelajar yang berada di dalamnya.bilik darjah bersifat multidemensi kerana dipenuhi oleh pelajar yang melalui proses pengajaran dan pembelajaran dalam suatu tempoh masa yang tertentu (Haliza \& Samuel, 2014)

\subsection{KESIMPULAN}

Berdasarkan kajian ini, pengkaji telah membincangkan perkara yang berkaitan objektif, persoalan kajian, metodologi kajian dan dapatan data terhadap penggunaan tempat yang sering digunakan oleh guru Pendidikan Islam khusus dalam penyampaian pedagogi bagi pelajar di peringkat menengah rendah. Pola dapatan kajian telah membentuk sebuah Model Tempat Pengajaran dan Pembelajaran (P\&P) Pendidikan Islam yang dapat dilihat di ruang implikasi dan cadangan kajian. Sehubungan itu, adalah diharapkan model ini dapat memberi panduan khusus kepada setiap guru Pendidikan Islam untuk memvariasikan tempat pengajaran dan pembelajaran agar lebih berkesan dan menarik serta dapat dihayati dan diterapkan oleh para pelajar dalam kehidupan seharian mereka.

\section{Rujukan}

Al-Quran Al-Karim (319 Tafsir Mengikut Tema Istimewa untuk Muslimah). (2013). Karya Bestari Sdn.Bhd. 174

Abd. Halim, Tamuri. (2013). Ke Arah Memperkasa Tamadun Islam Melalui Pendidikan. Kertas kerja Dibentangkan di Seminar Pertama Pendidikan dan Penyelidikan Islam, Universiti Teknologi Malaysia dan Persatuan Cendikiawan Islam Malaysia.

Abd. Halim, Tamuri, Adnan, Yusopp, \& Kamisah, Osman. (2004). Keberkesanan Kaedah Pengajaran dan Pembelajaran Pendidikan Islam ke Atas Pembangunan Diri Pelajar. Bangi: Universiti Kebangsaan Malaysia.

Abd. Halim, Tamuri, Shahrin, Awaluddin, \& Tajul Ariffin, Nordin. (2003). Fungsi Surau dan Keberkesanannya dalam Pengajaran dan Pembelajaran Pendidikan Islam: Satu Kajian di sekolah-sekolah Menengah Negeri Selangor. Bangi: Universiti Kebangsaan Malaysia.

Agatha Francis, Umbit (2011). Kepuasan Pelajar Terhadap Perkhidmatan dan Kemudahan Pelajar Terhadap Perkhidmatan dan Kemudahan di Pusat Sumber IPG Kampus Batu Lintang. Jurnal Penyelidikan IPG Kampus Batu Lintang, 10, 1-14

Ahmad, Mohd Salleh. (2000). Pendidikan Islam; Falsafah, Pedagogi, dan Metodoligi. Selangor: Penerbit Fajar Bakti Sdn.Bhd.

Ashinida, Aladdin, Afendi, Hamat, \& Mohd Shabri, Yusof. (2004). Penggunaan PBBK (Pembelajaran Bahasa Berbantukan Komputer) dalam pengajaran dan Pembelajaran Bahasa Arab Sebagai Bahasa Asing: Satu Tinjauan Awal. GEMA: Online Journal of Language Studies, 4(1), 1-16.

Bogdan, R. C., \& Miklen, S. K. (2003). Qualitative Research for Education: An Introduction to Theory and Methods. Boston: Allyn \& Bacon.

Emmer, E. T, Evertson, C. M., Sanford, J. P., Clements, B. S., \& Worsham, M. E. (1993). Classroom Management for Secondary Teacher. Second Edition. Englewood Cliffs: NJ: Prentice Hall.

Falcinelli, Floriana, \& Laici, Chiara. (2011). ICT in Classroom: A New Teaching And Learning Strategy. Kertas kerja Dibentangkan di EdMedia: World Conference on Educational Media and Technology 2011, Lisbon, Portugal. http://www.editlib.org/p/3837 
GPIS1. (2012). Ciri-ciri Kecemerlangan Guru Pendidikan Islam. Dalam Nazirah Hamdan, Kajian Lapangan Ph.D. Surau S1, SMK Taman Desa Skudai: FTI, UTM. 114

GPIS2. (2012). Ciri-ciri Kecemerlangan Guru Pendidikan Islam. Dalam Nazirah Hamdan, Kajian Lapangan Ph.D. Surau S1, SMK Taman Universiti: FTI, UTM. 1-34

GPIS3. (2012). Ciri-ciri Kecemerlangan Guru Pendidikan Islam. Dalam Nazirah Hamdan, Kajian Lapangan Ph.D. Perpustakaan S3, SM Tun Fatimah Johor Bahru: FTI, UTM. 1-60.

GPIS4. (2014). Ciri-ciri Kecemerlangan Guru Pendidikan Islam. Dalam Nazirah Hamdan. Kajian Lapangan Ph.D. Bilik Kaunseling S4, Sekolah Menengah Agama Al-Quran Waddin: FTI, UTM. 1-16.

GPIS5. (2014). Ciri-ciri Kecemerlangan Guru Pendidikan Islam. Dalam Nazirah Hamdan, Kajian Lapangan Ph.D. Surau Al-Hikmah S5, Sek. Men. (P) Sultan Ibrahim Johor Bahru: FTI, UTM. 1-19.

GPIS6. (2014). Ciri-ciri Kecemerlangan Guru Pendidikan Islam. Dalam Nazirah Hamda, Kajian Lapangan Ph.D. Bilik Kaunseling S5, Maktab Sultan Abu Bakar Johor Bahru: FTI, UTM. 1-17.

Haliza, Hamzah, \& Samuel, Joy Nesamalar. (2014). Pengurusan Bilik Darjah dan Tingkah Laku. Selangor: Oxford Fajar Sdn.Bhd.

Hamdi, Ishak, Ab. Halim, Tamuri, Rosadah, Abd. Majid, \& Safani, Bari. (2012). Amalan Pengajaran Guru dalam Pengajaran dan Pembelajaran Pendidikan Islam di Sekolah Kebangsaan Pendidikan Khas (Masalah Pendengaran). Journal of Islamic and Arabic Education, 4(2), 11-24.

Jamaludin, Badusah, Muhammad, Hussin, \& Abd. Rashid, Johar. (2000). Inovasi Dan Teknologi Dalam Pengajaran Dan Pembelajaran. Selangor: AJM Publishing Enterprise.

James, Ang Jit. (2014). Pengurusan Bilik Darjah Strategi-strategi Mewujudkan Komunikasi Pembelajaran Berkesan. Selangor: PTS Akademis.

Johari, Surif, Nor Hasniza, Ibrahim, \& Rohaya, Abu Hassan. (2014). Tahap Amalan dan Pengintegrasian ICT dalam Proses Pengajaran dan Pembelajaran Sains. Sains Humanika, 2(4), 13-18.

Kamarul Azmi, Jasmi, Ab. Halim, Tamuri, \& Mohd Izham, Mohd Hamzah. (2011). Penerapan Matlamat Pendidikan Islam oleh Guru Cemerlang Pendidikan Islam: Satu Kajian Kes di beberapa buah Sekolah Menengah di Malaysia. Sains Humanika, 55(1), 37-53

KPM. (2012). Dasar Pendidikan Kebangsaan. Putrajaya: Kementerian Pelajaran Malaysia.

KPM. (2013). Pelan Pembangunan Pendidikan Malaysia 2013-2025 (Pendidikan Prasekolah hingga Lepasan Menengah. Putrajaya: Kementerian Pendidikan Malaysia.

Masoud, Hashemi, Masoud, Azizinezhad, \& Masoumeh, Farokhi. (2012). Power Point as an Innovative Tool for Teaching and Learning in Modern Classes. Procedia Social and Behavioral Sciences, 31, 559 - 563

Merriam, Sharan B. (2002). Qualitative Research In Practice: Example For Discussion And Analysis. San Francisco: Jossey-Bass. 3-17.

Mohd Faeez, Ilias, \& Kamarul Azmi, Jasmi. (2012). Aplikasi Bahan Bantu Mengajar Rasulullah S.A.W. dalam Pengajaran dan Pembelajaran Ibadah Khususiah dari Perspektif Muhammad Fu'ad Abdul Baqi dalam Kitab Al-Lu'lu' Wal Marjan. Kertas Kerja Dibentangkan di Seminar Antarabangsa Perguruan dan Pendidikan Islam [SEAPPI2012], 8-9 March 2012, Le Grandeur Palm Resort, Senai.

Mohd Mokhtar, Shafii (2003). Masjid Sebagai Pusat Pendidikan dan Penjanaan Umat Cemerlang. Jurnal Pendidikan Islam, 10, 41-56.

Mohd Noor Badlilshah, Abdul Kadir. (2007). Gaya Pembelajaran: Satu Kajian Deskriptif Terhadap Pelajar Kolej Matrikulasi Perak. Kertas Kerja Dibentangkan di Seminar Kebangsaan Isu-isu Pendidikan Negara Ketiga: Dasar dan Perlaksanaan, Selangor.

Mohd Yusuf, Ahmad. (2010). Pengajaran dan Pembelajaran Pendidikan Islam di Masjid. http://eprints.oum.edu.my/550/551/pengajaran_dan_pembelajaran.pdf.

Nor Diana, Abd. Rahman, Nor Ezan, Omar, \& Zailani, Shafie. (2011). Pusat Sumber Sekolah Sebagai Ejen Kecemerlangan Sijil Pelajaran Malaysia (SPM): Kajian Ke atas Pelajar Baru Sesi Julai-November 2010, UITM Johor. Johor: Universiti Teknologi Mara.

Othman, Lebar. (2014). Penyelidikan Kualitatif Pengenalan Kepada Teori dan Metode. Tanjung Malim Perak: Universiti Pendidikan Sultan Idris

P1S3. (2012). Ciri-ciri Kecemerlangan Guru Pendidikan Islam. Dalam Nazirah Hamdan, Kajian Lapangan Ph.D. Perpustakaan S3, SMK Tun Fatimah Johor Bahru: FTI, UTM. 1-50.

P1S7. (2014). Ciri-ciri Kecemerlangan Guru Pendidikan Islam. Dalam Nazirah Hamdan, Kajian Lapangan Ph.D. Surau S7, Sek. Men. Keb. Dato' Penggawa Barat Pontian: FTI, UTM. 1-11.

P2S7. (2014). Ciri-ciri Kecemerlangan Guru Pendidikan Islam Dalam Nazirah Hamdan, Kajian Lapangan Ph.D. Surau S7, Sek. Men. Keb. Dato' Penggawa Barat: FTI, UTM. 1-11.

PAGPIS5. (2014). Ciri-ciri Kecemerlangan Guru Pendidikan Islam. Dalam Nazirah Hamdan, Kajian Lapangan Ph.D. Bilik Guru-guru Kanan S5, Sek. Men. (P) Sultan Ibrahim Johor Bahru: FTI, UTM. 1-19.

PAGPIS7. (2014). Ciri-ciri Kecemerlangan Guru Pendidikan Islam. Dalam Nazirah Hamdan, Kajian Lapangan Ph.D. Bilik Ketua Bidang S7, Sek. Men. Keb. Dato Penggawa Barat Pontian: FTI, UTM. 1-23.

R1GPIS7. (2014). Ciri-ciri Kecemerlangan Guru Pendidikan Islam. Dalam Nazirah Hamdan, Kajian Lapangan Ph.D. Bilik Guru Senior S7, Sek. Men. Keb. Dato' Penggawa Barat: FTI, UTM. 1-17.

R2GPIS3. (2012). Ciri-ciri Kecemerlangan Guru Pendidikan Islam. Dalam Nazirah Hamdan, Kajian Lapangan Ph.D. Bilik Guru S3, SMK Tun Fatimah Johor Bahru: FTI, UTM. 1-66.

Ruzita, Selamat, Ungku Norulkamar, Ungku Ahmad, Noor Zainab, Abd. Razak, Lokman, Ali, Azian, Abd. Aziz, Fauziah, Sheikh Ahmad, \& Aminah, Ahmad Khalid. (2004). Kajian ke atas Persekitaran Pengajaran dan Pembelajaran Fakulti Pengurusan dan Pembangunan Sumber Manusia: Ke Arah Pembentukan Persekitaran yang Optimum dalam Mencapai Kecemerlangan Pengajaran dan Pembelajaran. Skudai: Universiti Teknologi Malaysia.

Sang, Mook Soon. (2010). Penyelidikan dalam Pendidikan Perancangan dan Pelaksanaan Penyelidikan Tindakan. Puchong, Selangor: Penerbitan Multimedia Sdn.Bhd.

Shahril, Marzuki. (1997). Kajian sekolah berkesan di Malaysia: Model lima faktor. Doktor Falsafah, Universiti Kebangsaan Malaysia, Bangi.

Tajul Ariffin, Nordin , \& Abd. Rahim, Kurais. (1987). KBSM dari Pandangan Kita. Jurnal Pendidikan Islam, 12, 44-69.

Tejo, Nurseto. (2012). Membuat media pembelajaran yang menarik. Jurnal Ekonomi \& Pendidikan, 8(1), 19-35 